\title{
VIEWPOINT
}

\section{Good clinical practice and informed consent are inseparable}

\section{Doyal}

It is now widely accepted that clinicians should negotiate rather than dictate what is in the best interests of patients.
Correspondence to: Professor Len Doyal, Department of Human Science and Medical Ethics, St Bartholomew's and the Royal London School of Dentistry, Turner Street, London El 2AD;

I.doyal@mds.qmw.ac.uk
$\mathrm{T}$ Wo decades ago it was common for clinicians to minimise the importance of respecting the autonomy of patients in clinical practice and medical research - their ability and need to make plans about the personal consequences of treatment for them and others. Indeed, the word "autonomy" was not in common use in professional guidance about good practice, and most clinicians I met had no clear understanding of its meaning. The idea that patients might have a right to self determination in the context of medical care tended to be swamped by the excessive paternalism characteristic of the medical profession at the time.

In the UK, medical ethics has evolved partly as a critical reaction to such paternalism. Rather than "Doctor knows best", other slogans now sum up the mood of the time. "Partnership in care" is a favourite of the current government. It is now widely accepted that clinicians should negotiate rather than dictate what is in the best interests of patients.

\section{PROFESSIONAL AND LEGAL REGULATION AND ADVICE}

Nowhere is this change of moral opinion clearer than in current professional and legal guidance about obtaining informed consent from competent patients. Professionally, the General Medical Council states that: "Successful relationships between doctors and patients depend on trust. To establish that trust you must respect patients' autonomy-their right to decide whether or not to undergo any medical intervention ... . [They] must be given sufficient information, in a way that they can understand, in order to enable them to make informed decisions about their care." The Council has the power to de-register any clinician found to be in breach of this principle and is more likely to do so in the future than ever before. A wide range of other professional organisations-including the British Medical Association, the Royal Colleges, and the various defence associations-all endorse the same moral principles. ${ }^{2-4}$ The same can be said of professional and regulatory bodies in other countries. ${ }^{56}$ Several editorials on informed consent in a receut issue of Heart appear to underline and embrace this moral consensus. ${ }^{7-9}$

The law also endorses the moral importance of respect for autonomy within medicine. To avoid a claim of battery, the consent of patients to treatment must be based on information "in broad terms" about the nature of, and reason for, proposed treatment choices. ${ }^{10}$ For example, separate consent must be provided for distinct follow on procedures. Patients should be informed about which procedures within a treatment plan are independent and consent obtained for each component therapy, rather than for the plan as if it were as an indistinguishable whole. This will be so, even if refusal of one component may seriously compromise the patient's prospects for recovery. ${ }^{8}$

Equally, to avoid a claim of negligence, the information disclosed to patients, when obtaining consent, about risks must be "reasonable" in the eyes of the court. Leaving aside breaches of professional duty so obvious that they "speak for themselves", this has traditionally been determined by the "Bolam test". The Bolam test is where expert witnesses, nearly always from within the medical profession, are asked to confirm the appropriateness of a particular aspect of medical care. The care is regarded as appropriate if the experts convince the court that a relevant reasonable body of professional opinion would endorse the course of action that was actually taken. In the case of consent the issue would be the amount and accuracy of information disclosed by a doctor and contested by a patient. ${ }^{11}$ The appropriateness of this will be irrespective of :

(1) the degree that claimants believe that they were morally entitled to specific information they were not given

(2) the degree of harm they suffered as a result

(3) the extent to which their claim for a financial remedy may be supported by public opinion.

Therefore, consent assessed as appropriate by the Bolam test is judged by a "professional standard" which may be judged inappropriate outside the profession if it disregards the patient and is based solely on the views of clinicians.

In the past some patients have not been given the information about therapeutic risks when they clearly should have been, despite the fact that the consent procedure they underwent passed the Bolam test. Such moral breaches of the duty to respect the patient's autonomy have recently led the judiciary to question the relevance of the Bolam test as an appropriate standard for determining what patients should be told about risks. Case law appears to be evolving toward a more patient centred standard of disclosure. ${ }^{12}$ When faced with a decision about how much information to reveal, the most morally appropriate behaviour is not to speculate about what expert colleagues might do but rather 
to ask what a "reasonable person" would wish to know in the circumstances of the patient. In practice, this should be interpreted as meaning what clinicians themselves would wish to know in similar circumstances or would want to be communicated to their close friends and relatives.

\section{"The moral and legal acceptability of consent depends upon more than the transmission of appropriate information to patients"}

Finally, the moral and legal acceptability of consent depends upon more than the transmission of appropriate information to patients. ${ }^{13}$ Their choices must not be coerced by members of their health care team or by other third parties (for example, relatives). Equally, patients must be competent to consent: to be able to understand, remember, deliberate about, and believe clinical information given to them about their specific treatment options. Otherwise, consent would lack autonomy since it was made while patients were not in control of their cognitive or emotional capacities. Yet competence is task oriented: patients should not be thought of as either totally competent or incompetent. Judgments about competence to consent should depend on the particular circumstances involved. For example, a child may be competent to consent to a blood test but incompetent to do the same for chemotherapy.

Both professional guidance and legal precedent reinforce these provisions for valid consent. For example, in one famous case, a young adult woman was not allowed to refuse a life-sustaining blood transfusion partly on the grounds that she had been coerced by her mother (a Jehovah's witness) ${ }^{14}$ In another, a schizophrenic detained under the Mental Health Act was deemed competent to refuse life-sustaining treatment, despite the fact that he was also regarded as incompetent to refuse other psychiatric care. ${ }^{15}$

In general, therefore, the clinical duty to obtain proper informed consent is now widely believed to be an essential component of good clinical practice.

\section{CAN A PROFESSIONAL BACKLASH BE SUSTAINED?}

Some clinicians have found it difficult to embrace this professional and legal consensus. In a recent issue of Heart, Beresford and colleagues argue that their research and that of others confirm that some patients want little or no information about therapeutic risks and that the standard of the disclosure of the reasonable patient should not be applied to them. ${ }^{16}$ They believe that patients should be asked about how much information they want and given it accordingly. Further, Ågård and colleagues question the appropriateness of striving for high standards of consent within some cardiological research involving acute conditions that potentially compromise competence. ${ }^{17}$ They argue that in such circumstances, competent patients may feel unable to understand the information they require to give proper consent. Of course, if patients are incompetent then the issue of consent does not arise. Yet with competent patients, who are quite ill, is it not cruel to force information on them that they do not want?

These papers should be understood within a wider context of research confirming that competent patients are sometimes unable to understand clinical information, especially information about risks. ${ }^{18-22}$ Equally, patients soon forget such information, suggesting that they do not believe it to be of as much moral importance as those who set themselves up as moral defenders of their rights. ${ }^{23}$ Indeed, some patients explicitly state that they want their clinician/clinical researcher to make the final decision about their care. ${ }^{24}$ On this basis it might be argued that informed consent is often an illusion, even when clinicians go through the motions of obtaining it, and that more time should be spent instead on the provision of a high standard of technical care and of research.
In my opinion these arguments are flawed on both empirical and moral grounds. ${ }^{25}$

- Empirical research suggests that the understanding of patients improves with the provision of information structured according their needs and with the use of a variety of strategies for good communication. ${ }^{26}$ Not surprisingly poor communication may lead to poor understanding. ${ }^{27}$

- In the context of informed consent, even if memory is poor, this fact in itself does not constitute evidence that reduces the moral importance of relevant information disclosure. Many of us may recall little of the detailed cognitive processes that have accompanied important life decisions. It does not follow that in making such decisions, we did not require the best and most relevant information we could get in order make them. Also, the appearance of poor memory may not reflect reality if its background is communication so poor that it precludes the existence of anything clear to remember. Again, the communication skills of clinical researchers doing this kind of work will be important when conclusions are drawn about good practice.

- The fact that patients may say that they want their clinicians to make final decisions about their care does not mean that they do not want to be involved in it. In fact, such patients may be simply be stating the obvious-that clinicians must still make the final decision to proceed with treatment after informed consent has been given. On the other hand, care should be taken from drawing the wrong conclusions from interviews with distressed and vulnerable patients who, because of their dependence on clinical expertise, may feel intimidated and less than honest about their real feelings.

\section{"Respect for the patient's autonomy in clinical practice} is of great moral significance"

Respect for the patient's autonomy in clinical practice is of great moral significance. Our ability as humans to reason, to choose, and to plan ahead helps to differentiate us from animals. This is why respect for these characteristics is so linked to the principle of respect for human dignity. Many people have fought and died to defend this principle and the human right to informed consent that follows from it. Moral concern about the violation of this right by clinicians has informed many recent critiques of medical practice (for example, those relating to relevant events in Bristol and Alder Hey). Not to take this right seriously threatens lasting damage to the medical profession and to the trust that is so important for its success.

Therefore, it may be true that some patients state that they wish little information about treatment, prognosis or risks, especially if they are interviewed in the immediate aftermath of a dramatic clinical intervention. Yet it does not follow from such findings that it is in the best interests of such patients not to be given the information they need to be capable of reasoned choice. Their refusal can itself only be valid if it is properly informed to some minimally accepted level encompassing basic core information about what their refusal will practically mean in the management of their illness. ${ }^{28}$ Suppose that an operation has serious risks and a patient does not want to know about them. For this refusal to be properly informed, that patient needs at least to understand that his/her proposed treatment does entail significant risks, whatever further details are not revealed. If they are not told this they can have no idea what they are refusing or how their refusal might compromise their best interests. Furthermore, before clinicians take the serious step of minimising disclosure of information to patients, they should ensure that this is what patients actually want, including multiple checks over time and self monitoring as regards the quality of their own 
communication with the patient. Frightened and anxious patients may well not wish to obtain further information from clinicians on whom they know they clinically depend and they find that they often cannot understand.

\section{CONCLUSION}

This article has outlined good practice in obtaining informed consent and discussed its moral and legal foundations. Arguments that question these foundations have been rejected, at least in the terms in which they are usually presented. The real enemy of proper informed consent in medicine is not the inability of adult patients to engage in the process. Rather it is insufficient resources to train clinicians to communicate more successfully with their patients and inadequate staff to allow enough available time for this essential communication to occur.

This conclusion does not mean that incompetent patients who are unable to provide informed consent should not be treated. In life threatening emergencies, the moral and legal doctrine of necessity ensures that appropriate care can be provided. ${ }^{13}$ As regards elective care, however, the doctrine of informed consent continues to be of moral and professional significance where there is time for consultation with legal proxies of children (that is, those with parental responsibility), with competent children themselves or where competent adults nominate other adults to represent their best interests if they become incompetent. ${ }^{29}$ In the UK adults cannot act as legal proxies for other adults. However, in discharging the responsibilities to determine the best interests of incompetent adults, it is appropriate for clinicians to consult acceptably nominated representatives. To be effective, such consultation demands a level of disclosure of information, analogous to that pertaining to informed consent. Finally, for the purposes of research involving incompetent patients, "assent" (that is, agreement) should ordinarily be obtained from appropriate relatives in ways approved by an independent research ethics committee. ${ }^{29}$ Such committees should insist that effective assent depends upon a level of disclosure of information that will-in effect-be the same as it would for obtaining the consent of competent adult patients.

In short, even though it may still not—strictly speaking-be part of UK law, the doctrine of informed consent is morally and professionally here to stay, and watch this space as regards future changes in the law. This doctrine should be taken seriously by all clinicians and medical researchers. Lawyers or accountants could not have a professional relationship with clients who were unwilling or unable to learn and discuss diagnostic and prognostic information about their legal and financial problems. It is widely accepted that the professional goal of such relationships is to enable the client to make legal or financial decisions that optimise their interests and their autonomy. Morally, clinical relationships should be viewed in similar terms.

\section{REFERENCES}

1 General Medical Council, Seeking patients' consent: the ethical considerations. London: GMC, 1999:2.

3 British Medical Association, Report of the consent working party: incorporating consent tool kit. London: BMA, 2001.

3 Department of Health, Reference guide to consent for examination or treatment. London: Department of Health, 2001.

4 Royal College of Surgeons, The surgeons's duty of care. London: RCS, 1997.

5 American Medical Association. Code of medical ethics. Chicago: AMA, 1997.

6 Canadian Medical Association. Code of ethics. Ottawa: CMA, 1996.

7 Kurbaan AS, Smith S, Mills PG. Consent in cardiac practice. Heart 2001;86:593-4.

8 Beresford NW. Consent issues in cardiology. Heart 2001;86:595-6.

9 Docherty A, Oldroyd KG. Percutaneous coronary intervention: obtaining consent and preparing patients for follow on procedures. Heart 2001;86:597-8.

10 Chatterson v. Gerson [1981] 3WLR 1003

11 Bolam v. Friern HMC [1957] 2 All ER 118
12 Kennedy I, Grubb A. Medical law. London: Butterworths, 2000:704-13

13 Mason JK, McCall Smith RA. Law and medical ethics. London, Butterworths, 1999:244-88.

$14 \operatorname{Re} T$ [1992] 4 All ER 649.

$15 \operatorname{Re} C$ [1994] 1 All ER 819 (FD).

16 Beresford N, Seymore L, Vincent C, et al. Risks of elective cardiac surgery: what do patients want to know? Heart 2001;86:626-31.

17 Ågård A, Hermerén G, Herlitz J. Patients' experiences of intervention trials on the treatment of acute myocardial infarction: is it time to adjust the informed consent procedure to the patient's capacity? Heart 2001;86:632-7.

18 Rogers AE, Addington-Hall JM, Abery AJ, et al. Knowledge and communication difficulties for patients with chronic heart failure: qualitative study. BM 2000;321:605-7.

19 Macillop W, Stewart W, Ginsburg A, et al. Cancer patients' perceptions of their disease and its treatment. Br J Cancer 1988;58:355-8.

20 Sutherlund $\mathbf{H}$, Lockwood G, Till J. Are we getting informed consent from patients with cancer? J R Soc Med 1990;83:439-43.

21 Lloyd A. The extent of patients' understanding of risk? Quality in Health Care 2001;10(suppl 1):i14-18.

22 Grimes DA, Snively GR. Patients' understanding of medical risks: implications for genetic counselling and research. Obstet Gynecol 1999:93:910-14

23 Lloyd AJ, Hayes PD, London NJM, et al. Patients' ability to recall risk associated with treatment options. Lancet 1999;353:645.

24 Deher R. Physicians in healthcare management 8 . The patient-physician partnership: decision making, problem solving and the desire to participate. Can Med Assoc J 1994;154:423-7.

25 Doyal L. Informed consent: moral necessity or illusion. Quality in Health Care 2001;10(suppl I):i29-33.

26 Edwards A, Glyn E. How well do patients understand the concept of risk? Lessons for clinical risk communication. Quality in Health Care 2001;10(suppl 1):i9-13

27 Hall A. The role of effective communication in obtaining informed consent. In: Doyal L, Tobias J, eds. Informed consent in medical research. London: BM Books, 2000:291-8.

28 Doyal L. The moral importance of informed consent in medical research concluding reflections. In: Doyal L, Tobias J, eds. Informed consent in theory and practice. London: BMU Books, 2000:309-17.

29 Montgomery J. Health care law. Oxford: Oxford University Press, 1997:227-48;334-55.

\section{COMMENTARY}

Professor Doyal's viewpoint commented on a number of articles on the topic of patient consent that appeared in a recent issue of Heart (vol 86, No 6). We invited the authors of those articles to respond to Professor Doyle's comments, and below is the reply from one group.

\section{INFORMED CONSENT: ARE THERE ETHICALLY JUSTIFIED CONDITIONS FOR EXCEPTIONS?}

Are good clinical practice and informed consent inseparable? This depends, to some extent at least, on what is meant by "inseparable". Does this refer to a logical relation, on the assumption that "good clinical practice" by definition includes informed consent, to an empirical generalisation about current medical practice, or a normative statement about how it ought to be? Different arguments pro and contra are relevant depending on whether the statement is interpreted as a logical statement, an empirical generalisation, or as a normative statement.

We do not dispute the moral ground for the requirement of informed consent in general, ${ }^{1}$ and we agree with the statement that "the clinical duty to obtain proper informed consent is now widely believed to be an essential component of good clinical practice". Neither do we dispute that improved training in communication skills and more time for doctors to communicate with their patients would be a good thing - and probably make more patients participate in the decision process. ${ }^{2}$

What we wished to do in our paper ${ }^{3}$ was to discuss whether there might not be situations in which exceptions from the general requirement of informed consent would be acceptable. We hope that such a debate could help to define stringent 
and precise conditions when such exceptions could be morally and legally acceptable. One general assumption we share is the idea that such an exception is reasonable, if insisting on the requirement of informed consent causes more harm than good. In its turn, this presupposes a discussion of criteria of harm and benefit and who should decide about the relative magnitude of harm and benefit. Verification after the event by the patients in question could in certain situations be worth investigating. If there is a verification by the patients concerned, in the sense that they afterwards confirm that they think that an exception from the general requirement was ethically justified, then the concept of an exception from the general main rule is supported by referring to what the patients themselves want. If autonomy is taken seriously, references to what the patients say they want cannot be dismissed lightly.

Our ambition with the study published ${ }^{3}$ was not to suggest any radical changes regarding the informed consent procedure when a patient is suffering from an acute myocardial infarction and is a potential research subject, nor to draw any general conclusions from the results obtained. Instead, we wanted to elucidate the possible problems and disadvantages associated with the process of obtaining informed consent in this particular situation. Primarily we wanted to stimulate the debate on the following two issues:

1. Does a patient in the midst of a life crisis have to put his/her signature on a consent form in order to be included in an intervention trial?

2. Are there ethically justified alternatives to informed consent when a researcher wants to include a patient in a study, who is not capable of giving a free and informed consent in research?

We stated: "All possible measures to increase the autonomy of the patients under the prevailing circumstances should be carried out". Thus, we do not suggest that all patients with acute myocardial infarction should be treated as incompetent. However, what we have tried to do in our study is to bring forth and highlight empirical evidence, which seems to show that in this particular situation some patients do not have the capacity to give a true informed consent for study participation.

Professor Doyal adds another argument, to the effect that even if the patients afterwards do not remember anything, this does not reduce the moral importance of relevant information disclosure. The main question is what is meant by "relevant information disclosure", and who decides what this is. Suppose (a) that it is left to the patient to decide what is relevant information disclosure, (b) that additional information does not change the decision of the patient, and (c) they do not want this additional information, which conclusion should be drawn from this?

We claim that it is time to adjust the informed consent procedure to the patients' capacity in this particular situation. Moreover, the patient should be spared the "actual demand" of signing the consent form in the early phase of an acute myocardial infarction.

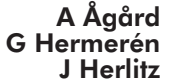

\section{REFERENCES}

1 Hermerén G. Informed consent from an ethical point of view. In: Westerhäll L, Phillips C, eds. Patient's Rights. Informed consent, access and equality. Stockholm: Nerenius \& Santérius, 1994:39-61.

2 Ågård A, Hermerén G, Herlitz J. Should cardiopulmonary resuscitation be performed on patients with heart failure. The role of the patient in the decision-making process? J Intern Med 2000;248:279-86.

3 Ågård A, Hermerén G, Herlitz J. Patients' experiences of intervention trials on the treatment of myocardial infarction: is it time to adjust the informed consent procedure to the patient's capacity? Heart 2001:86:632-7.

\section{ELECTRONIC PAGES}

\section{eHEART: www.heartinl.com}



he following electronic only articles are published in conjunction with this issue of Heart.

\section{Reversible left ventricular dysfunction "takotsubo" cardiomyopathy associated with pneumothorax Y J Akashi, M Sakakibara, F Miyake}

An 83 year old woman presented to the emergency department with chest pain and dyspnoea. Chest radiography showed pneumothorax of the left lung. Arteries were normal on coronary angiography. Left ventriculography showed asynergy of apical akinesis and basal hyperkinesis. Within 18 days, the asynergy improved without any specific treatment. In the present case the left ventricular dysfunction may have been induced by altered catecholamine dynamics as a result of pneumothorax.

(Heart 2002;87:el) www.heartjnl.com/cgi/content/full/87/2/el

\section{Myocardial infarction during adenosine stress test} J E Polad, L M Wilson

A 65 year old woman with history of ischaemic heart disease underwent standard adenosine stress test for myocardial perfusion imaging. She sustained inferior myocardial infarction during the final stages of the stress test. She was admitted to the coronary care unit and received thrombolytic treatment. The patient made an uneventful recovery. Adenosine is widely used for myocardial stress imaging tests and has a good safety profile. So far there has been only one other reported myocardial infarction during adenosine stress test, which was under special circumstances because three days before the test the patient had undergone percutaneous transluminal coronary angioplasty when a severe circumferential dissection was noted. The present patient's case highlights the need to be aware of rare but potentially serious complications of adenosine, even though it generally has an excellent safety record for use in myocardial stress testing.

(Heart 2000;87:e2) www.heartjnl.com/cgi/content/full/87/2/e2

Unusual case of refractory hypertension: late presentation of the mid-aortic syndrome

S Kumar, R W Bury, D H Roberts

A 58 year old patient with refractory hypertension, chronic renal failure, and widespread arterial bruits is described. Investigations found hypoplasia of the major blood vessels, particularly the aorta, leading to low flow nephropathy.

(Heart 2000;87:e3) www.heartjnl.com/cgi/content/full/87/2/e3 